Tribology International, 37 (5), pp. 415-422, 2004

\title{
Acoustic Emission during run-up and run-down of a power generation turbine
}

C. Zuluaga-Giraldo ${ }^{1}$, D. $\mathrm{Mba}^{1}$, M. Smart ${ }^{2}$

\author{
${ }^{1}$ School of Engineering, Cranfield University, Cranfield, Beds, MK43 0AL, UK \\ Tel: +44 (0) 1234 754681; Fax: +44 (0) 1234 751566; e-mail: d.mba@cranfield.ac.uk \\ ${ }^{2}$ Innogy plc, Windmill Hill, Whitehill Way, Swindon SN5 6PB, UK \\ Tel: +44 (0) 1793 877777; e-mail: MARK.SMART@innogy.com
}

\begin{abstract}
The measurement of Acoustic Emission (AE) activity at the bearings of power generation turbines is evolving into a viable complementary diagnostic technique especially adept at indicating the early stages of shaft-seal rubbing. This paper reports on an ongoing investigation on the application of acoustic emission for shaft-seal rub detection in power generation turbines. A pre-requisite in developing such a technique requires an understanding of the operational $\mathrm{AE}$ background noise.
\end{abstract}

The detection of shaft seal, and blade-case, rubbing with AE has been reported $[1,2,3]$. In these instances the observations of AE activity were associated with particular dynamic and process conditions known to cause such defects. However, the effect of variations of turbine loading on AE activity is unknown. This report presents observations of AE activity during the run-up and run-down of a 500MWatt steam turbine and is the first known document detailing correlations between AE, vibration and turbine loading.

Keywords:- Acoustic emissions, blade-case rubbing, condition monitoring, power generation turbines, shaft-seal rubbing. 


\section{Introduction}

To maximise efficiency, the seals and end-glands along the length of modern turbine units are in very close radial proximity to the rotating shaft. It is therefore unsurprising that contacts or rubs can readily occur between the high-inertia shaft and the surrounding components. Rubbing is an undesired contact between a rotating and stationary part and usually occurs as a secondary effect of some machine malfunctions such as unbalance, misalignment, thermal expansion, fluid-induced self excited vibration. Regardless of the exact relationship between cause and effect, the existence of rubbing is of great concern to the rotor dynamists engineer as it can develop into significant mechanical vibration leading to costly rotor damage. The most common form of diagnosing shaft-seal rubbing is vibration monitoring of the bearing pedestals via accelerometers and velocity transducers. However, Acoustic Emission (AE) offers the opportunity for identifying the onset of rubbing, and the location of the rub, from the bearing pedestal. The latter opportunity overcomes a drawback with current vibration monitoring techniques.

\section{Acoustic Emission}

Acoustic Emission (AE) is defined as the resulting transient elastic wave generated when strain energy is released suddenly within or on the surface of a material. These elastic waves cover a broad frequency range between $50 \mathrm{KHz}$ to $1 \mathrm{MHz}$.

On operational machines it is often only practical to take AE measurements from nonrotating members, such as the bearing housing. Consequently, AE signals originating 
from the rotating shaft will incur significant attenuation across the transmission path to the receiving $\mathrm{AE}$ transducer. This attenuation can be attributed to geometrical spreading across the surface or volume of the rotor, and, acoustic reflections at the bearing interfaces caused by acoustic impedance mismatches. Moreover, the $\mathrm{AE}$ signal will be further coloured by the characteristic frequency response of the $\mathrm{AE}$ transducer. However, Mba et al [4], Al Shaikh Mubarak et al [5] and Armor et al [2] have confirmed the transmissibility of AE waves across turbine rotors.

\section{Application of Acoustic Emission to health diagnosis on power generation turbines}

Successful application of AE to turbine health diagnosis have been reported by a few authors and all the authors have commented on the difficulty with interpreting data due to high background noise levels. Sato [1] investigated the use of AE to monitor seal rubbing on an operational 350MW steam turbine. AE sensors were attached to adjacent journal bearings whilst continuous rubbing was introduced at various rotor locations between the bearings with an aluminium sample. Sato stated that during tests on the steam turbines it proved difficult to judge rubbing phenomena solely on amplitude changes due to high background noise. However, Sato used the spectrum of the envelope AE waveform and showed that rotational frequencies of the turbine were generated with rubbing.

Armor et al. investigated the applicability of acoustic emission for shaft crack detection on a 200MW steam power generation turbine. Furthermore, the authors investigated transmission and background noise characteristics on steam turbine units 
during operation and outage. Sources of background noise were sited and included; steam flow, oil flow, aerodynamic turbulence at the blades, bearing friction, electromagnetic interferences, etc. AE sensors were fixed on the bearing ring, with the aid of wave-guides, and on the bearing pedestals for direct comparison of the propagation effects and the influence of background noise. In addition, Armor et al commented on successful transmission across a rotor using the Nielson source technique but sited that attempts to transmit a Nielson pulse across the unit during operation were not successful. The Nielson source technique involves breaking lead, 2H 0.5mm diameter, on a specified surface. Similarly, Mba et al [4] and Shaikh Mubarak et al [5] have recently shown transmissibility of AE across larger turbine units using the Nielson technique.

Armor et al stated that sources of AE noise during run-up of a steam turbine were attributed to the preheat steam flow through the turbine. It was noted that at full operational speed the steady-state noise was essentially 'white noise' and it was concluded that the inlet steam flow noise was not the dominant background source during full speed operation. Furthermore, Armor noted that the major source was probably in close proximity to the receiving sensor, such as bearing friction or aerodynamic turbine blade noise. It was commented that at full speed the AE r.m.s noise levels were $30 \mathrm{~dB}$ higher than the electronic noise levels of the acquisition system. In conclusion, the authors stated; 'the variety of possible interfering background noises during the various periods of turbine operation along with the limited choice of transducer mounting positions makes identification of crack growth emissions a difficult task.... . We are optimistic that this can be done ....' 
Mba et al [3] presented a case study highlighting the successful application of AE to seal rub detection. The findings presented reinforced the observations of Sato [1] on the modulating phenomenon of the AE waveform due to seal rubbing. Mba [3] noted a change in AE background noise levels after actions had been taken to eliminate the rub. The exact reason for this change was not presented but it was noted that the operating characteristics of the unit had changed.

\section{Acoustic Emission acquisition system}

A commercially available broadband piezoelectric AE transducer with a measurement bandwidth of $100 \mathrm{kHz}-1 \mathrm{MHz}$ was employed. The acquisition board was the Physical Acoustics Corporation AE-DSP-32/16 card. A magnetic clamp was employed to secure the AE receiving transducer onto the bearing casing. AE energy and r.m.s values were calculated in real time by the ADC controlling software. The software employed a hardware accelerator so that calculations could be performed in real time. The hardware accelerator takes each value from the ADC and squares it. The results are added into an accumulator for a programmable time interval, based on the user set time constant which in this instance was 100 mseconds. At the start of the time interval the accumulator is cleared and at the end of the time interval the accumulator value is stored. The r.m.s is then calculated by taking the square root of the sum of the accumulated squared ADC readings. The energy value computed was equivalent to the area under time the waveform and is measured in Atto-Joules ( $10^{-18}$ joules). The time interval for acquisition was set at 100 mseconds. Pre-amplification was set at $60 \mathrm{~dB}$. The signal output from the pre-amplifier was connected (i.e. via BNC/coaxial cable) directly to the data acquisition card. 


\section{Observations of AE operational background noise}

AE sensors were fitted onto a 550Mwatt steam power generation turbine in order to observe the run-up and run-down AE characteristics. The unit consisted of a highpressure cylinder, an intermediate cylinder and three low-pressure cylinders, see figure 1. Steady state background noise AE signatures were acquired from two lowpressure bearing pedestals, bearings 6 and 7, see figures 2 and 3. The bearing assembly and pedestal design were identical. A sampling rate of $4 \mathrm{MHz}$ was employed. It was observed that the frequency range of the operational AE background noise ranged from $75 \mathrm{KHz}$ to $300 \mathrm{KHz}$. It is interesting to note that amplitude and r.m.s levels from bearings 6 and 7 were $55 \mathrm{~dB}$ and $49 \mathrm{~dB}$ (maximum amplitude), and 59dB and 50dB (r.m.s) respectively above the electronic noise of the acquisition system. These values are much higher than Armor et. al [2] observed and is probably due to the variation in bearing design, housing/casing configuration and the size of turbine unit.

\section{Location of AE sensors}

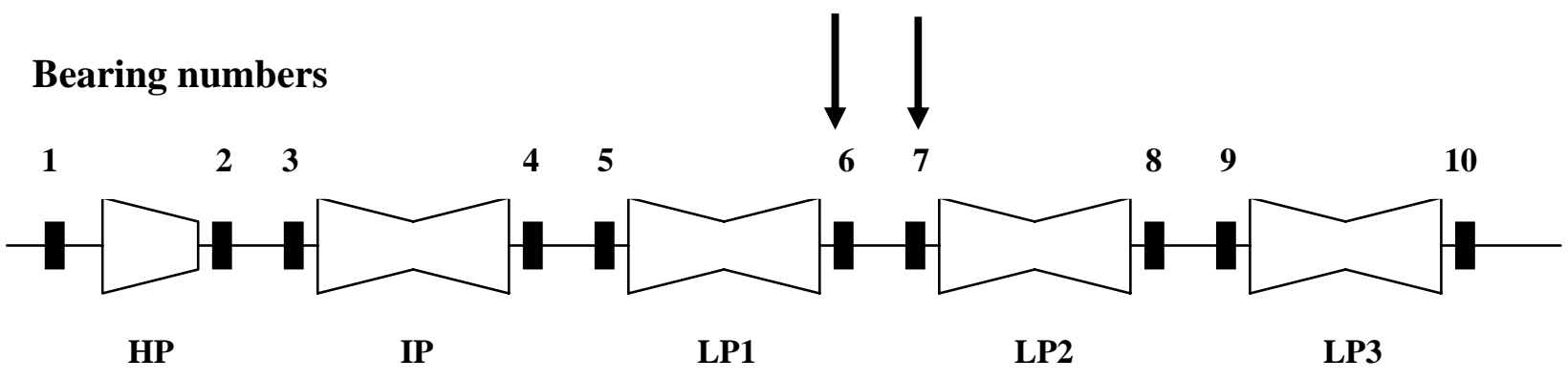

Figure 1 Schematic of part of the power generation turbine showing location of AE sensors 
Tribology I nternational, 37 (5), pp. 415-422, 2004
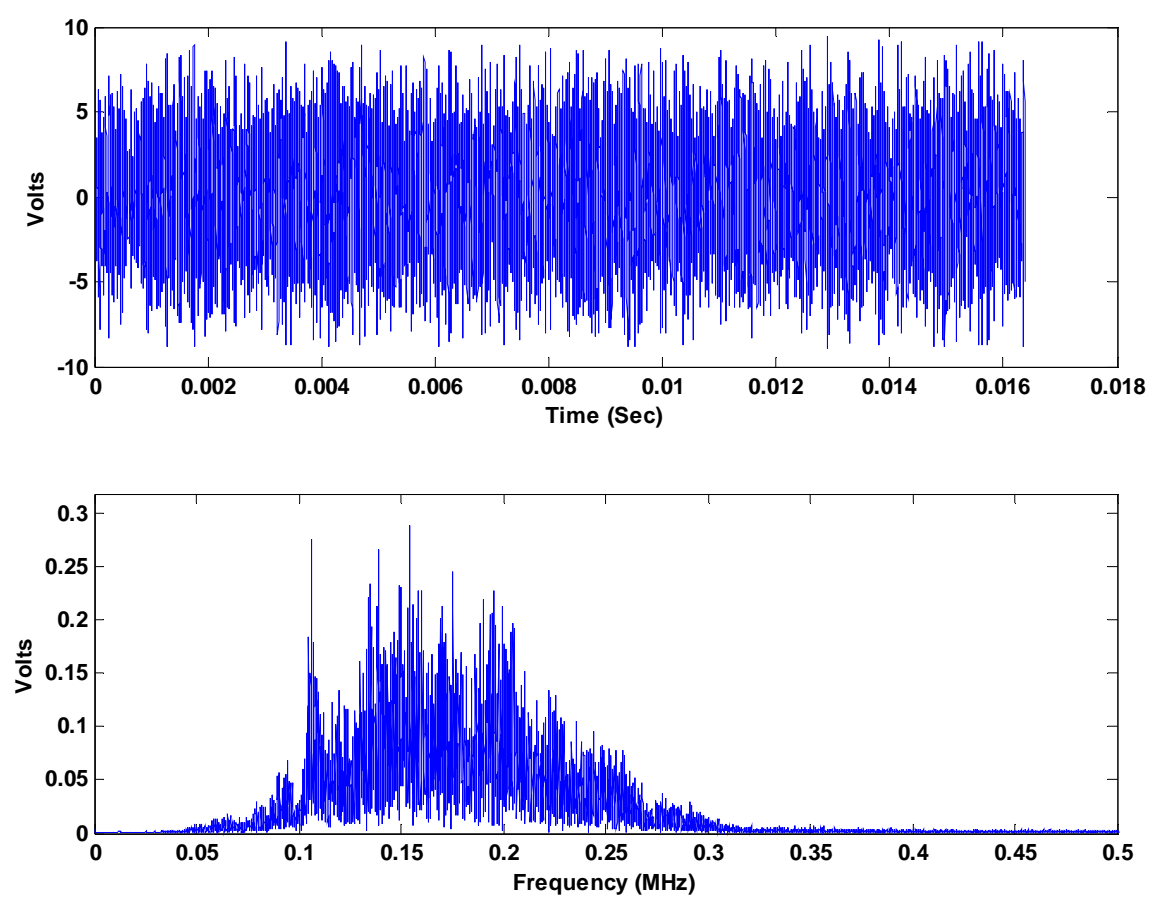

Figure 2 Typical operational background noise AE signature, with corresponding frequency spectrum; bearing 6
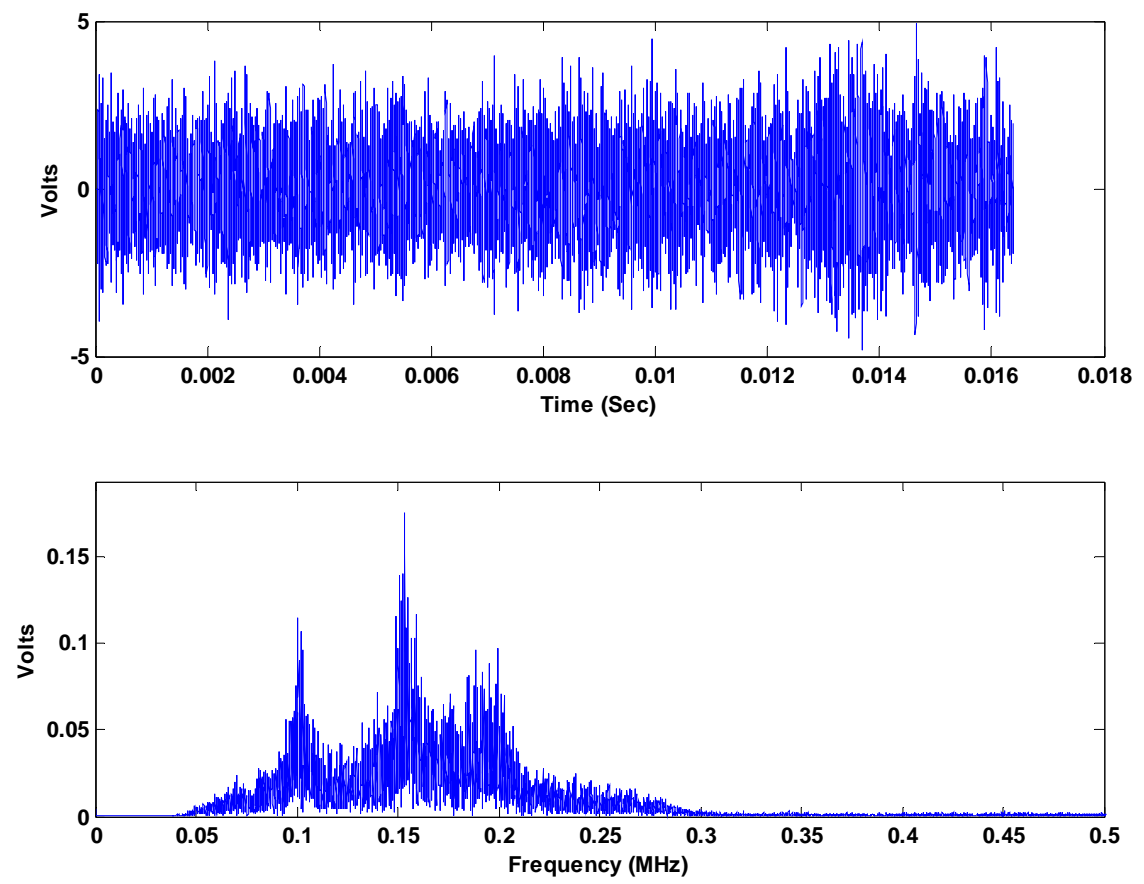

Figure 3 Typical operational background noise AE signature, with corresponding frequency spectrum; bearing 7 


\section{Observations of $\mathrm{AE}$ activity during run-up and run-down}

Acoustic Emission r.m.s values for bearings 6 and 7 are presented during the run-up and run-down of the turbine unit, see figures 4 and 5 . The total duration of the run-up and run-down was in excess of 70 hours. In addition, the load, rotational speed and r.m.s vibration levels for both bearings during run-up and run-down are presented in figures 6 to 9 . The parameters presented in figures 6 to 9 were normalised so that all available data on the three parameters, load, vibration r.m.s and rotational speed, could be displayed together. The load on the turbine unit is defined as the electric load on the generator which is proportional to the mass flow of steam within the turbine. Time scales shown on all figures, except figures 4 and 5, are not absolute but indicative of the duration of the activity presented in each figure. From figures 6 to 9 it was clearly evident that vibration r.m.s levels correlated with the loading on the turbine unit. 
Tribology I nternational, 37 (5), pp. 415-422, 2004

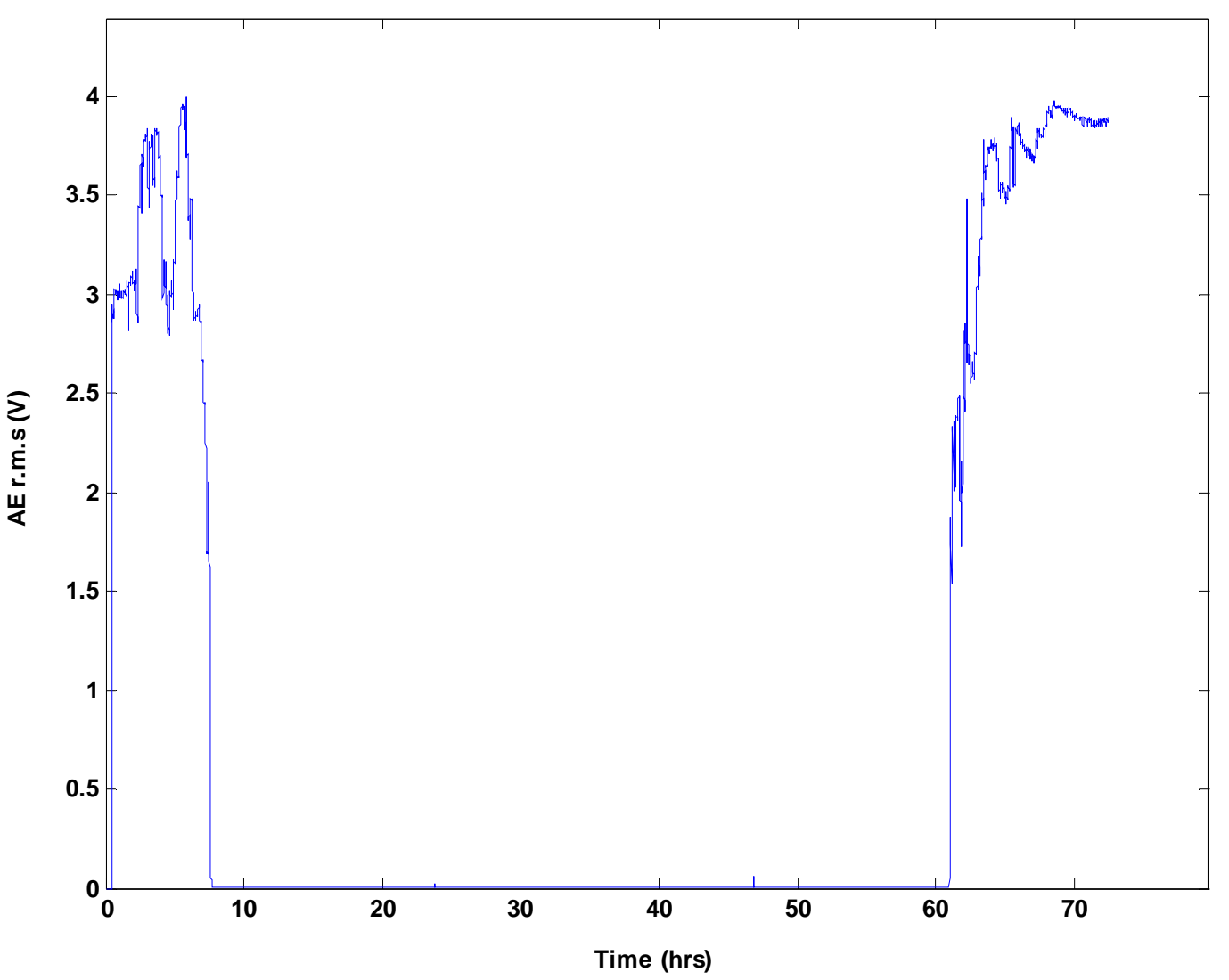

Figure 4 Run-up and run-down AE observations at bearing 6 


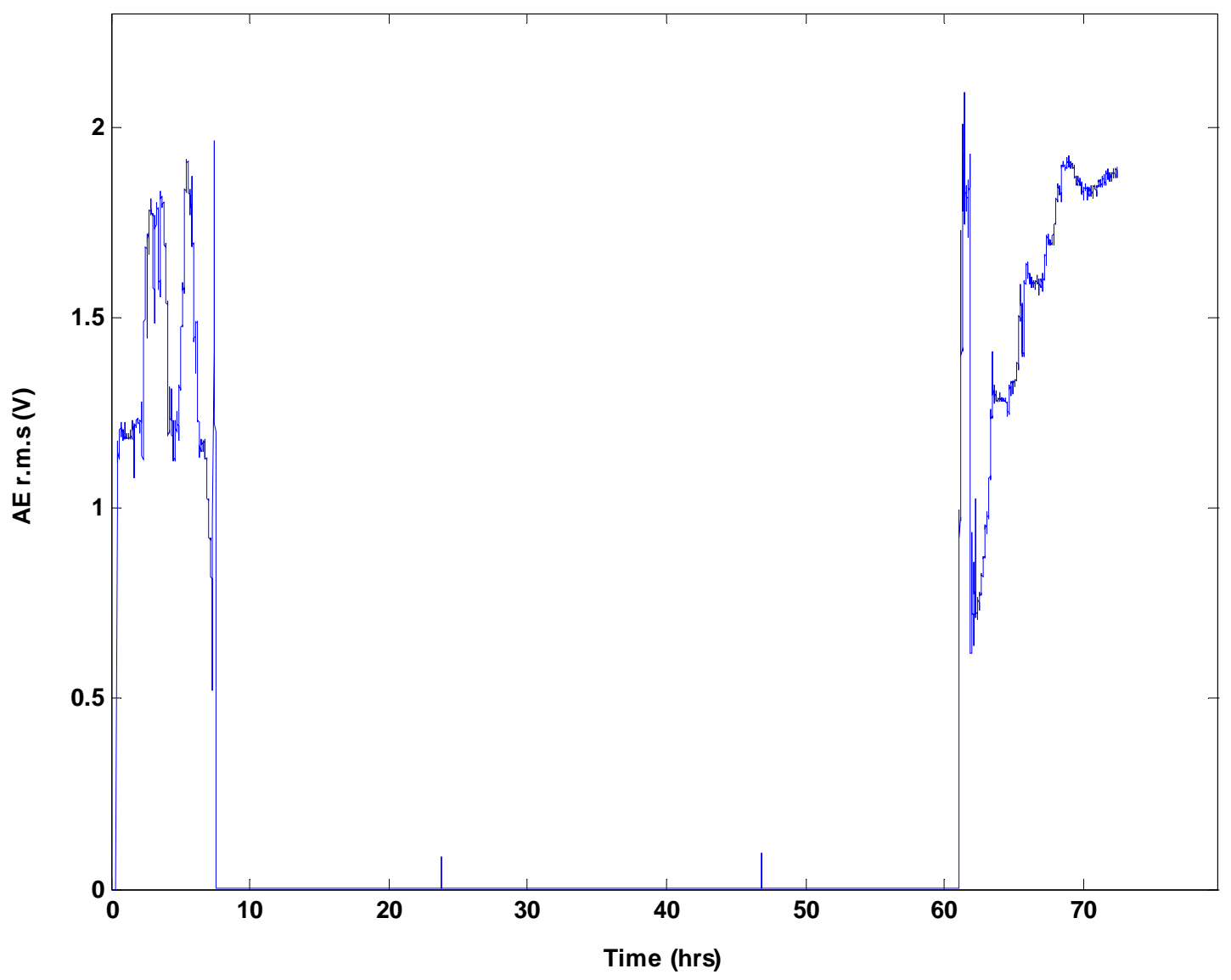

Figure $5 \quad$ Run-up and run-down AE observations at bearing 7

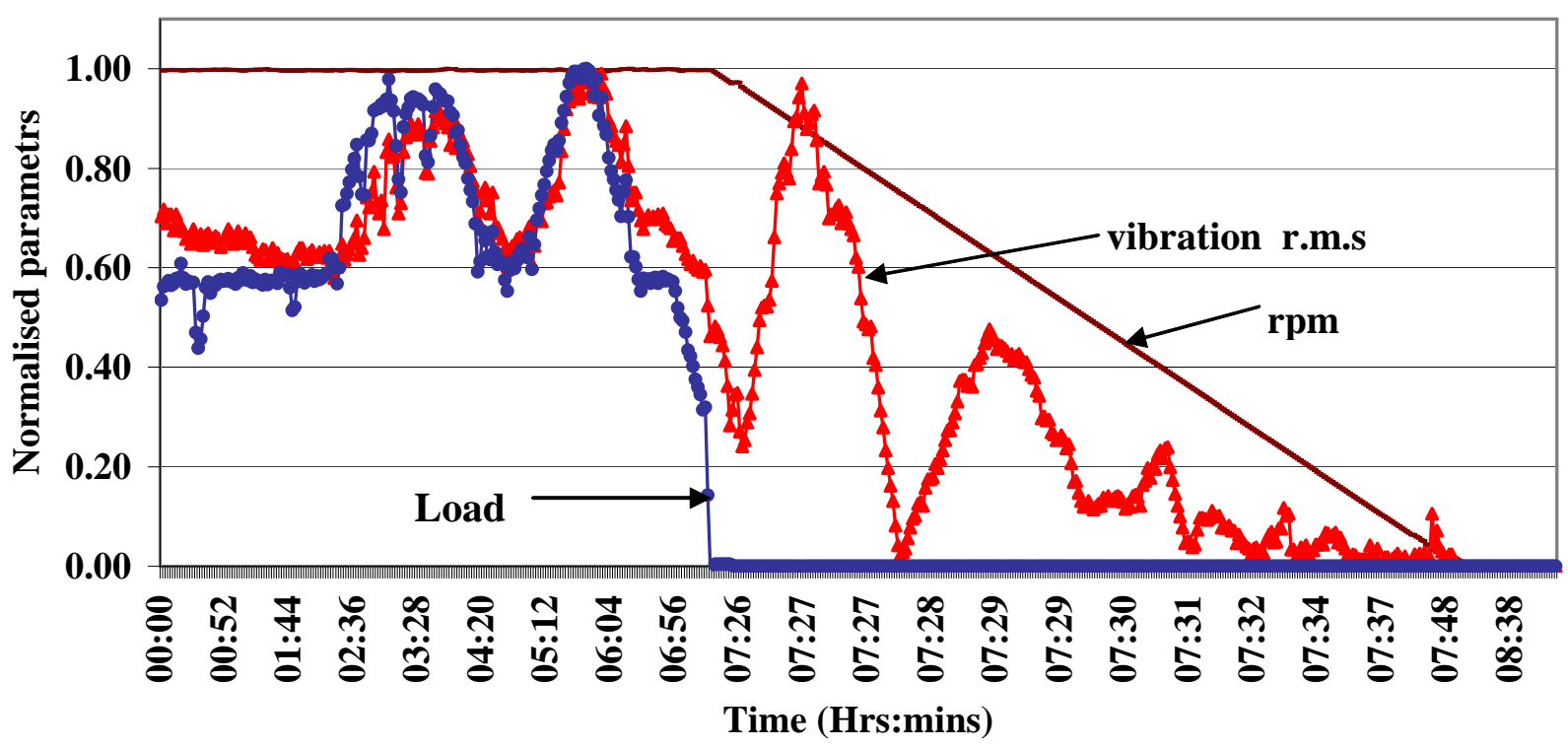

Figure 6 Load, speed and vibration r.m.s during run-down; bearing 6 


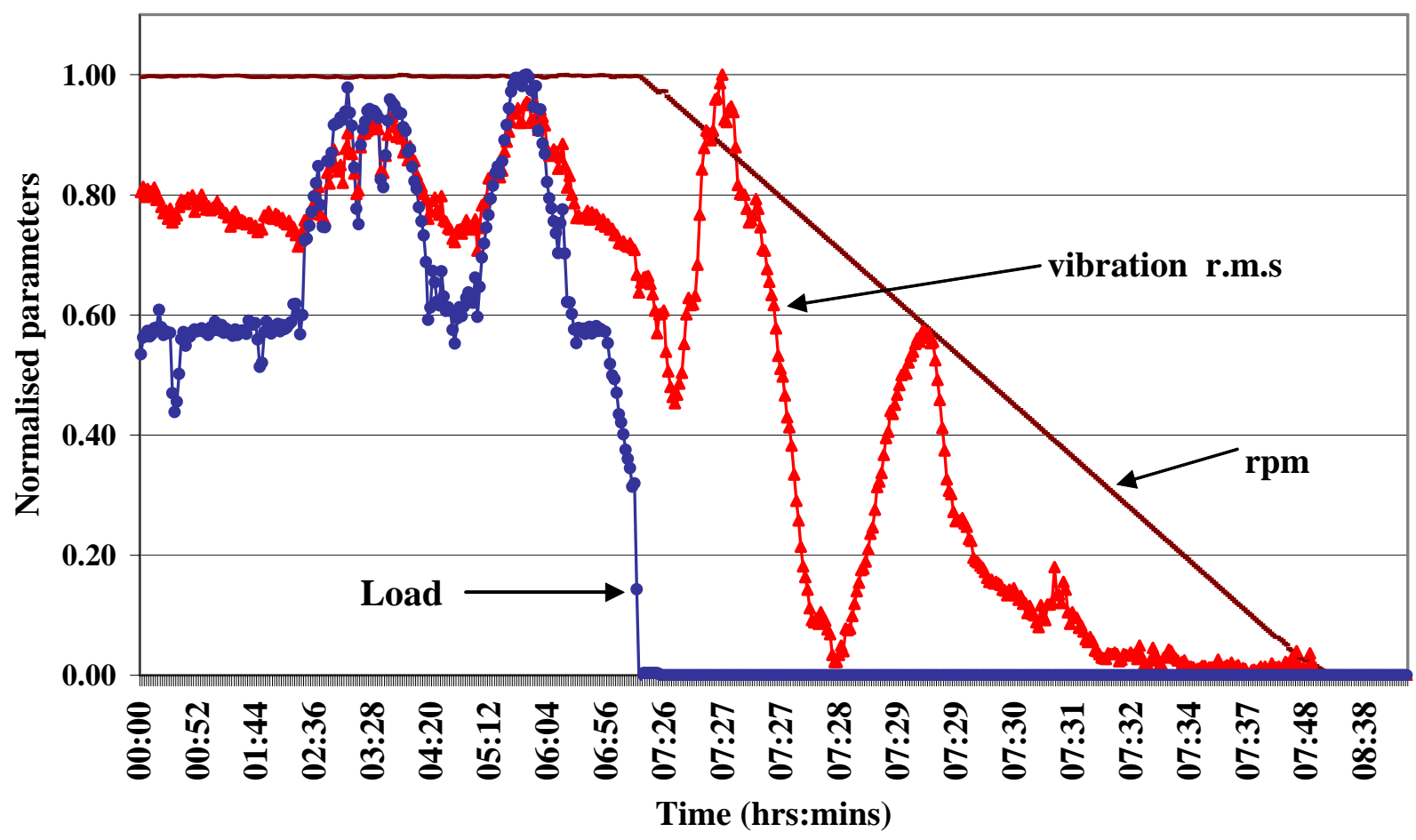

Figure $7 \quad$ Load, speed and vibration r.m.s during run-down; bearing 7

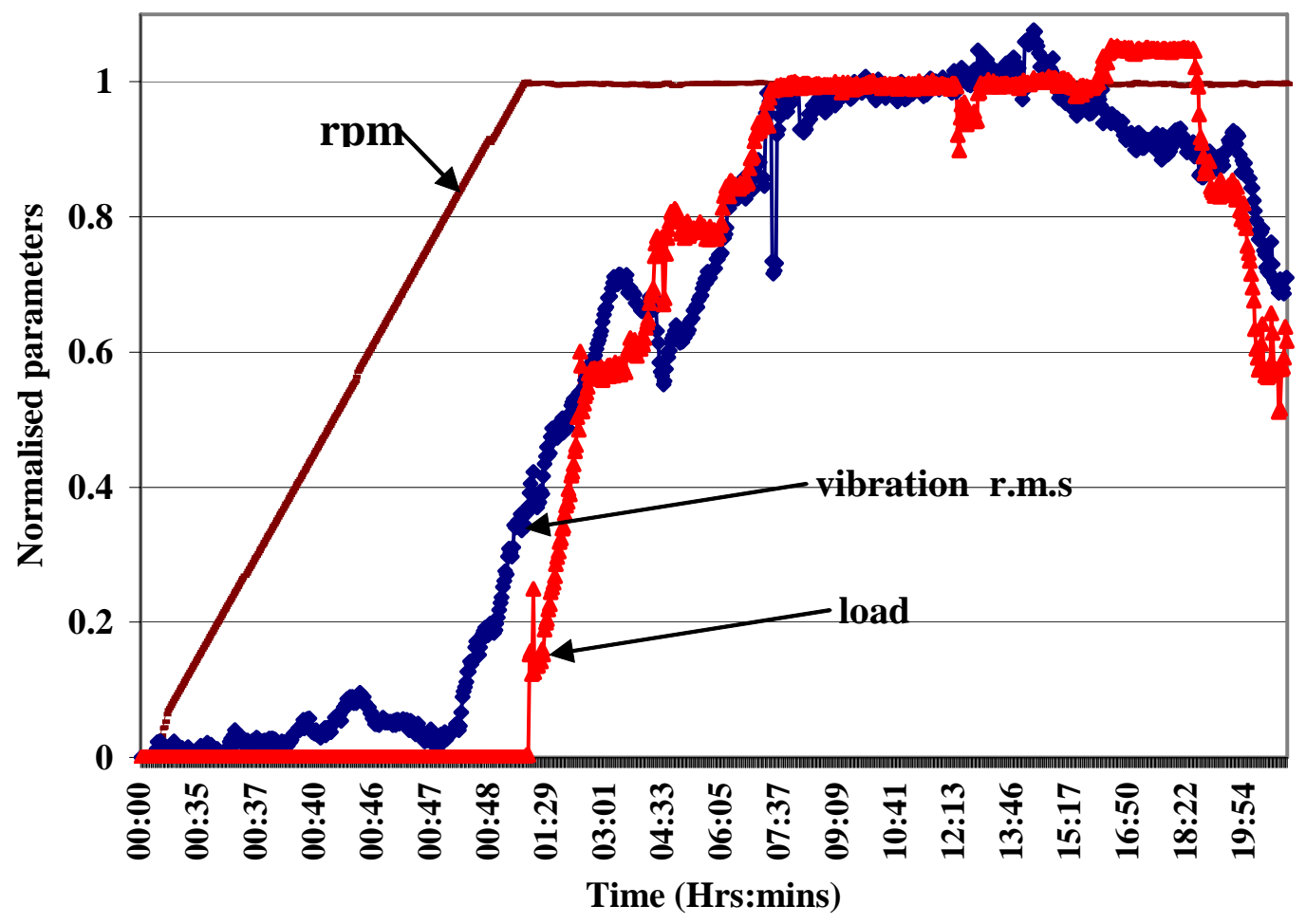

Figure 8 Load, speed and vibration r.m.s during run-up; bearing 7 


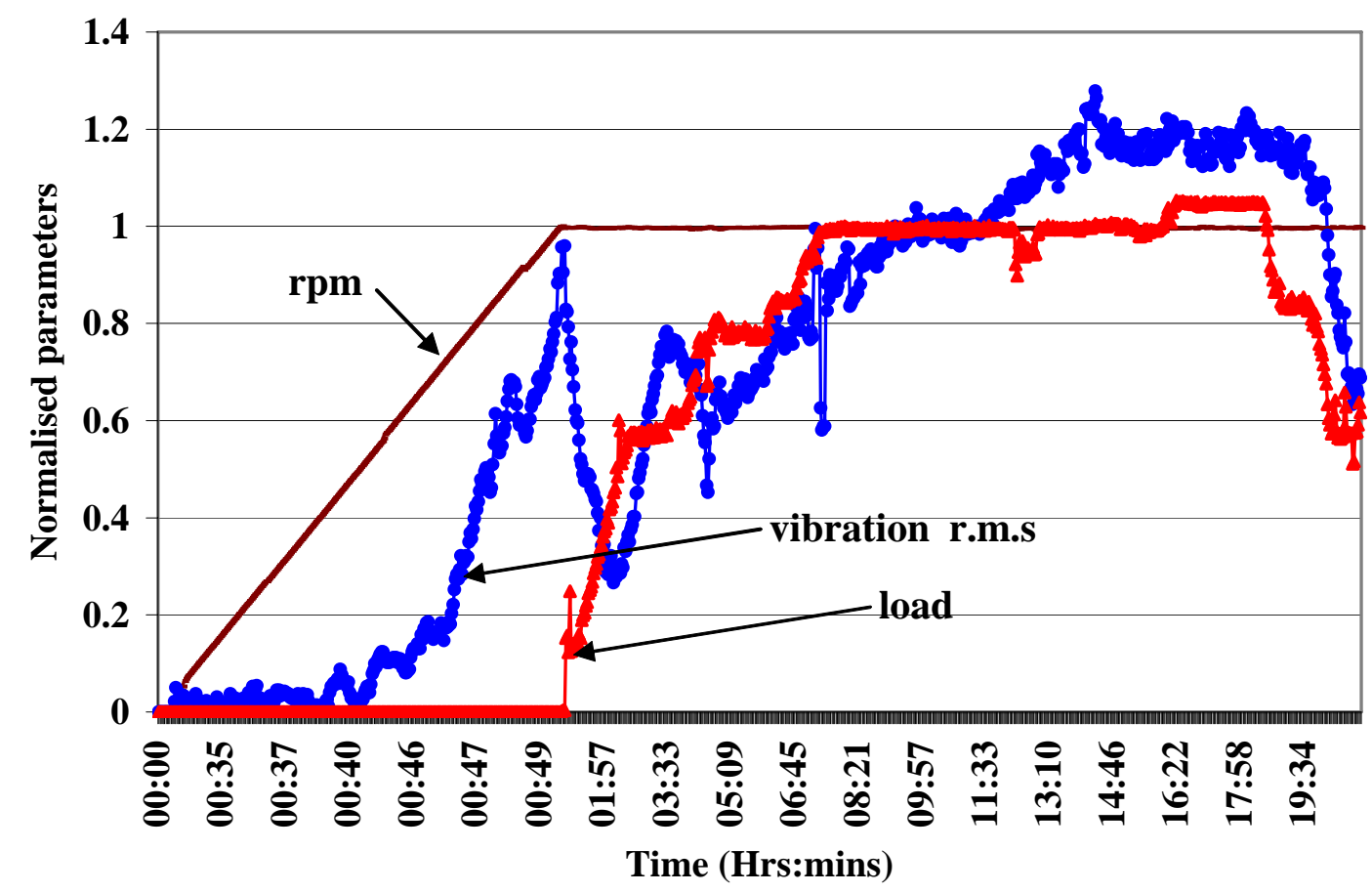

Figure 9 Load, speed and vibration r.m.s during run-up; bearing 6

The loading on the turbine unit prior to run-down is shown in figure 10 and figures 11 and 12 show the AE r.m.s activity observed on bearings 6 and 7 during run-down. Clearly the AE activity during run-down was influenced by the loading on the turbine unit. The same observations were evident during run-down, see figures 13 to 15 . 
Tribology International, 37 (5), pp. 415-422, 2004

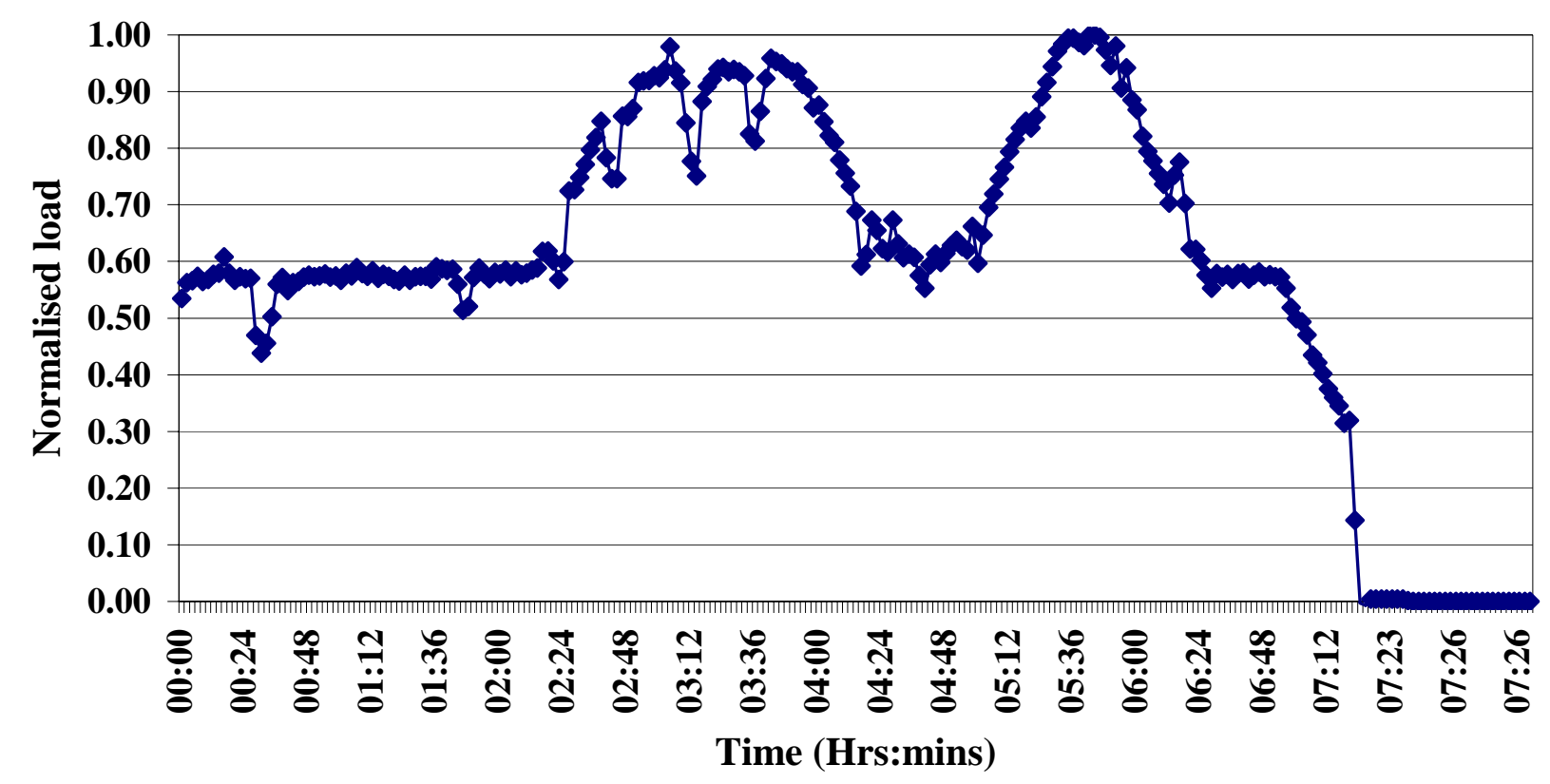

Figure 10 Load pattern during run-up

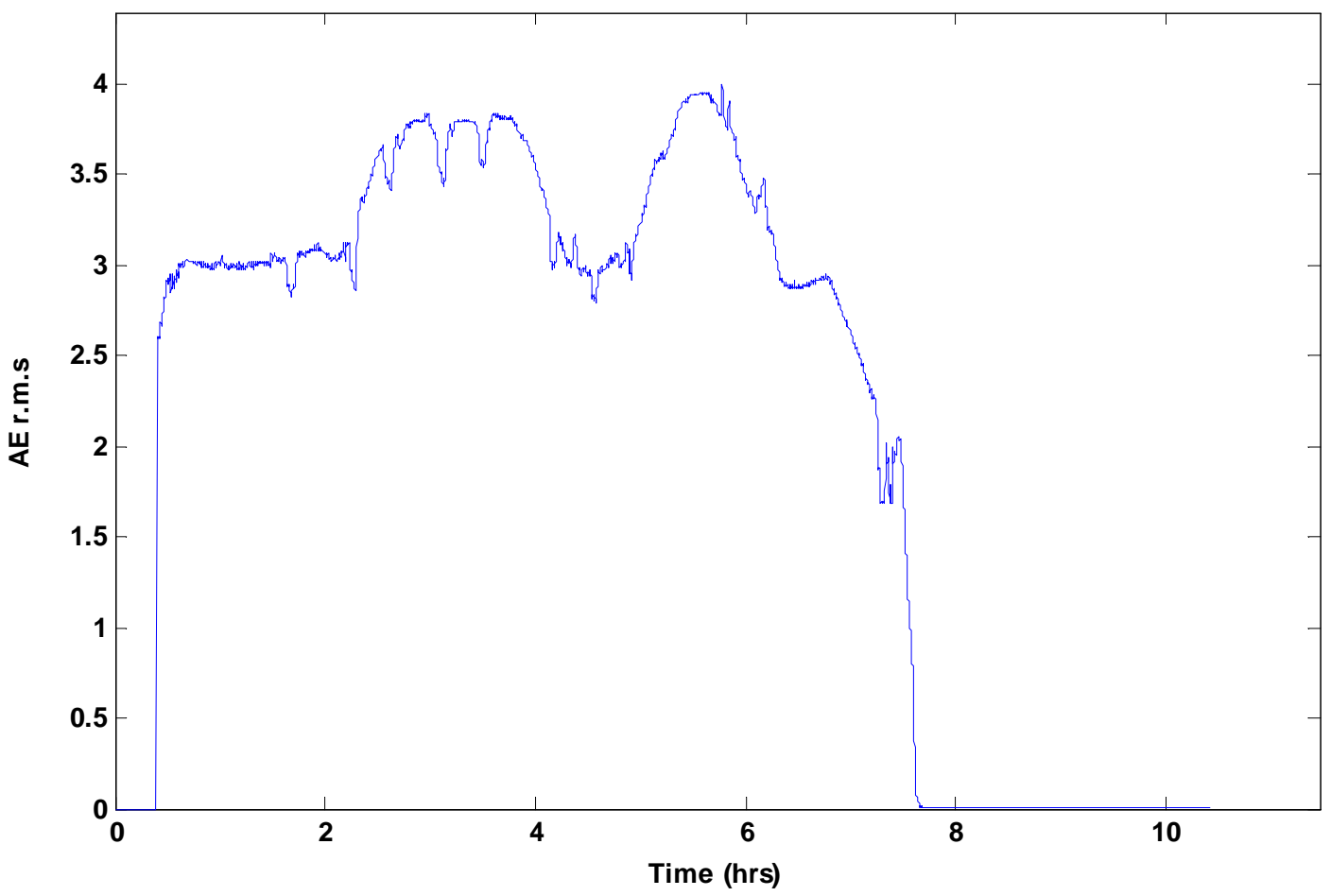

Figure 11 AE r.m.s (volts) activity during run-down; Bearing 6 
Tribology International, 37 (5), pp. 415-422, 2004

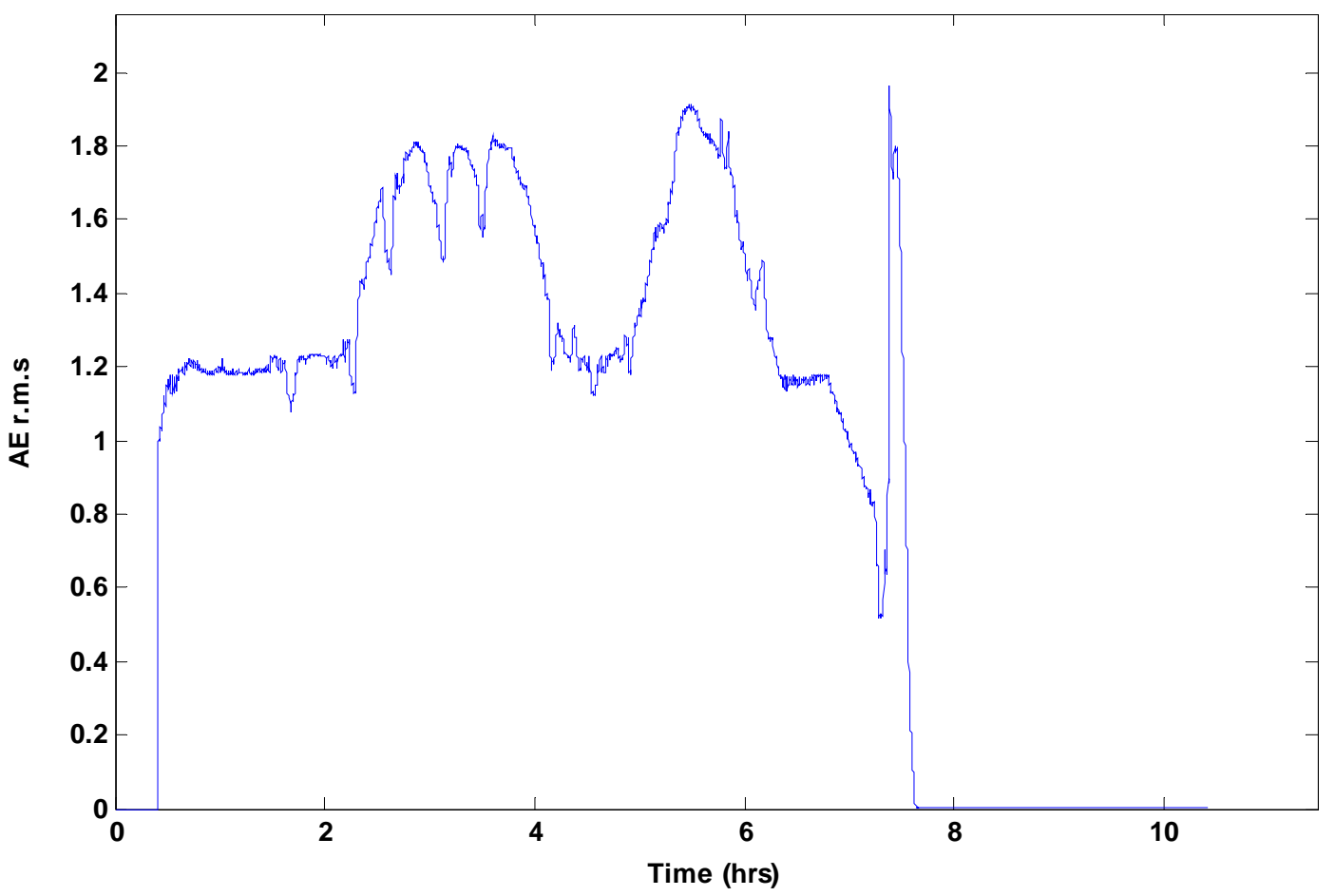

Figure 12 AE r.m.s (volts) activity during run-down; Bearing 7

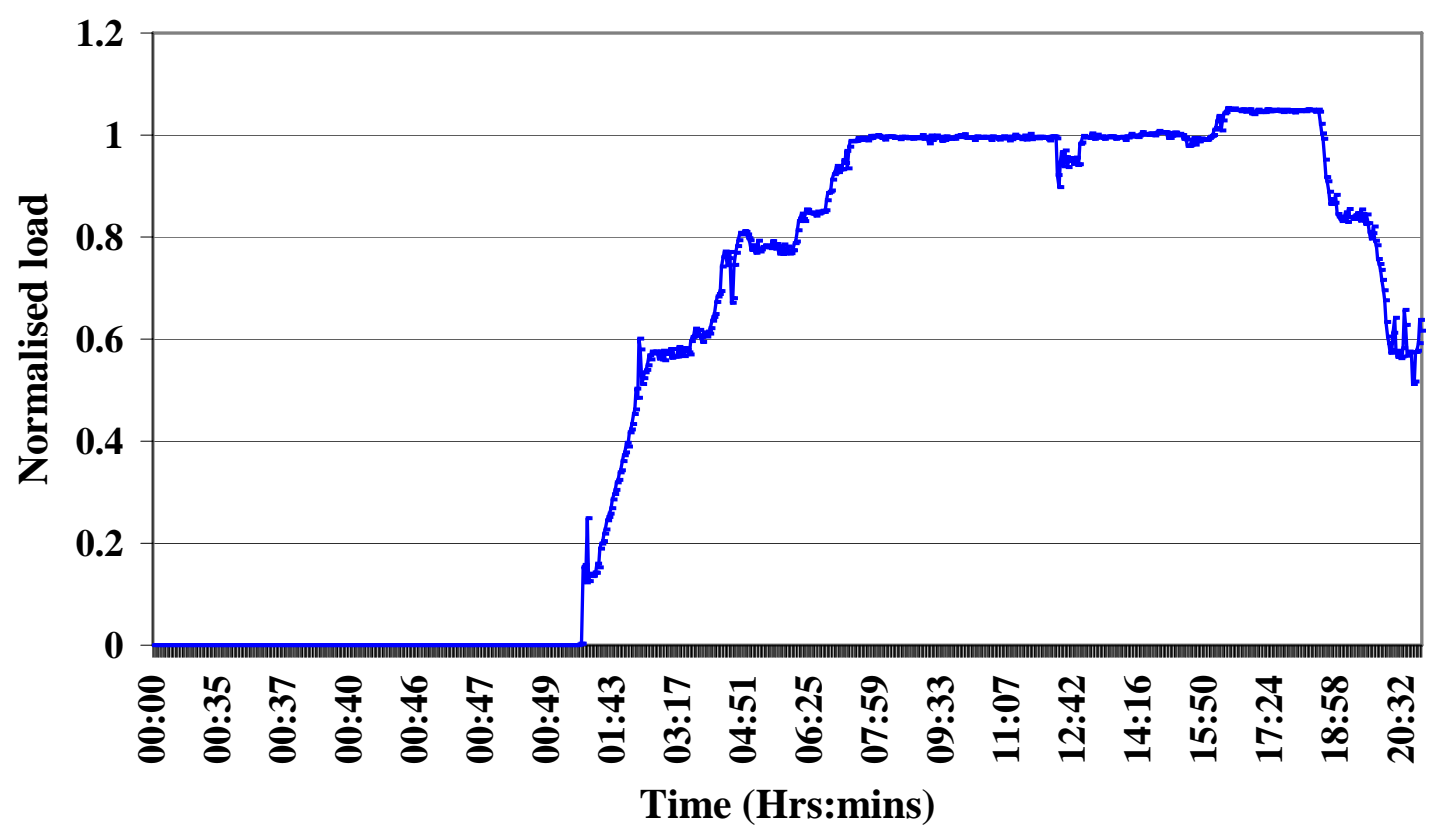

Figure 13 Load pattern during run-up 
Tribology I nternational, 37 (5), pp. 415-422, 2004

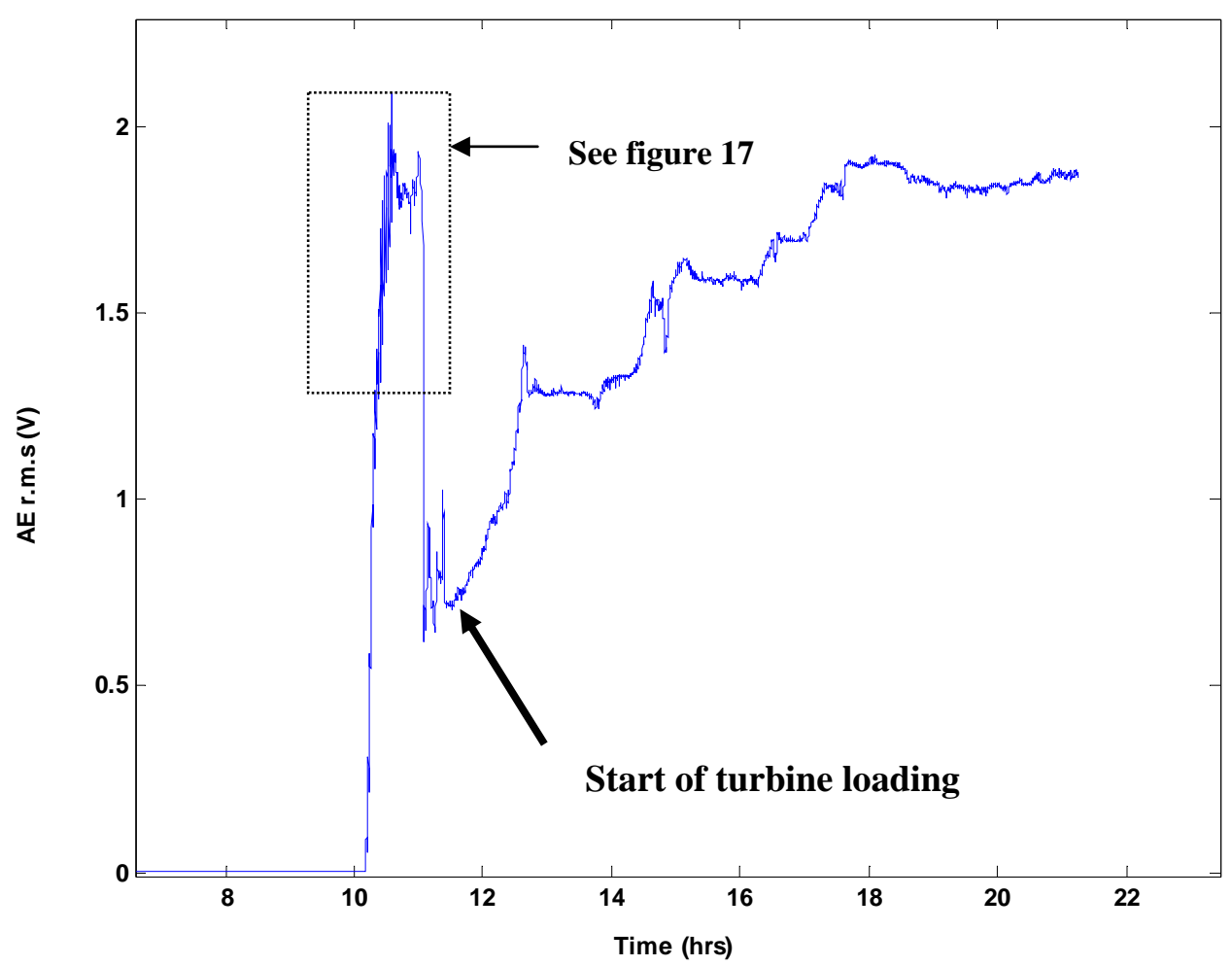

Figure 14 AE r.m.s (volts) activity during run-up; Bearing 7

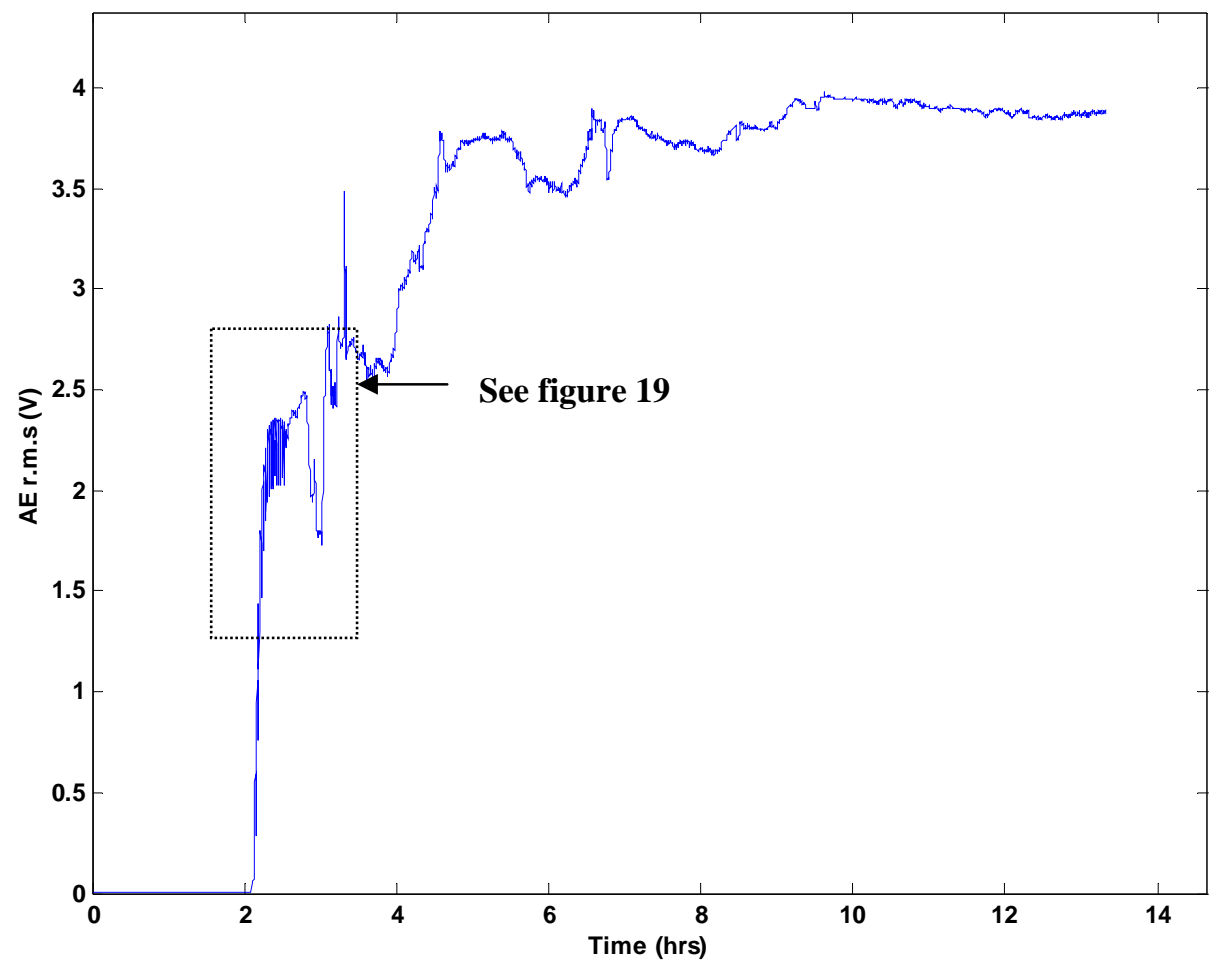

Figure 15 AE r.m.s (volts) activity during run-up; Bearing 6 


\section{Discussions}

From the results presented it was observed that $\mathrm{AE}$ and vibration r.m.s activity correlated with changes in load on the turbine unit. It was interesting to note that vibration r.m.s levels showed a marked increase on bearings 6 and 7 at about 7-hours and 26-minutes during the run down, see figures 6 and 7. This increase is attributed to the rotor passing through a critical speed. A corresponding increase was observed on AE r.m.s values at bearing 7, see figure 12. However, at the same instance in time on bearing 6, the AE r.m.s value did show a brief attempt to rise but this did not materialise, see figure 11. It was noted that during run-up on bearing 7 a similar rise of AE r.m.s was noted at the critical speed of the rotor, see figure 14. Again this was not observed on bearing 6, see figure 15. The AE r.m.s levels detected on bearing 7 at the critical (approximately 2- volts) was similar to that noted on bearing 6, though the underlying background noise levels from both bearings made this increase more pronounced on bearing 7. It is worth noting that the peak-to-peak displacement of the rotor shaft relative to the journal bearing did not show a relationship with load, however, a correlation between vibration r.m.s and shaft displacement was evident at the critical speed, as to be expected, see figure 16 . This was particularly true during run-down. 


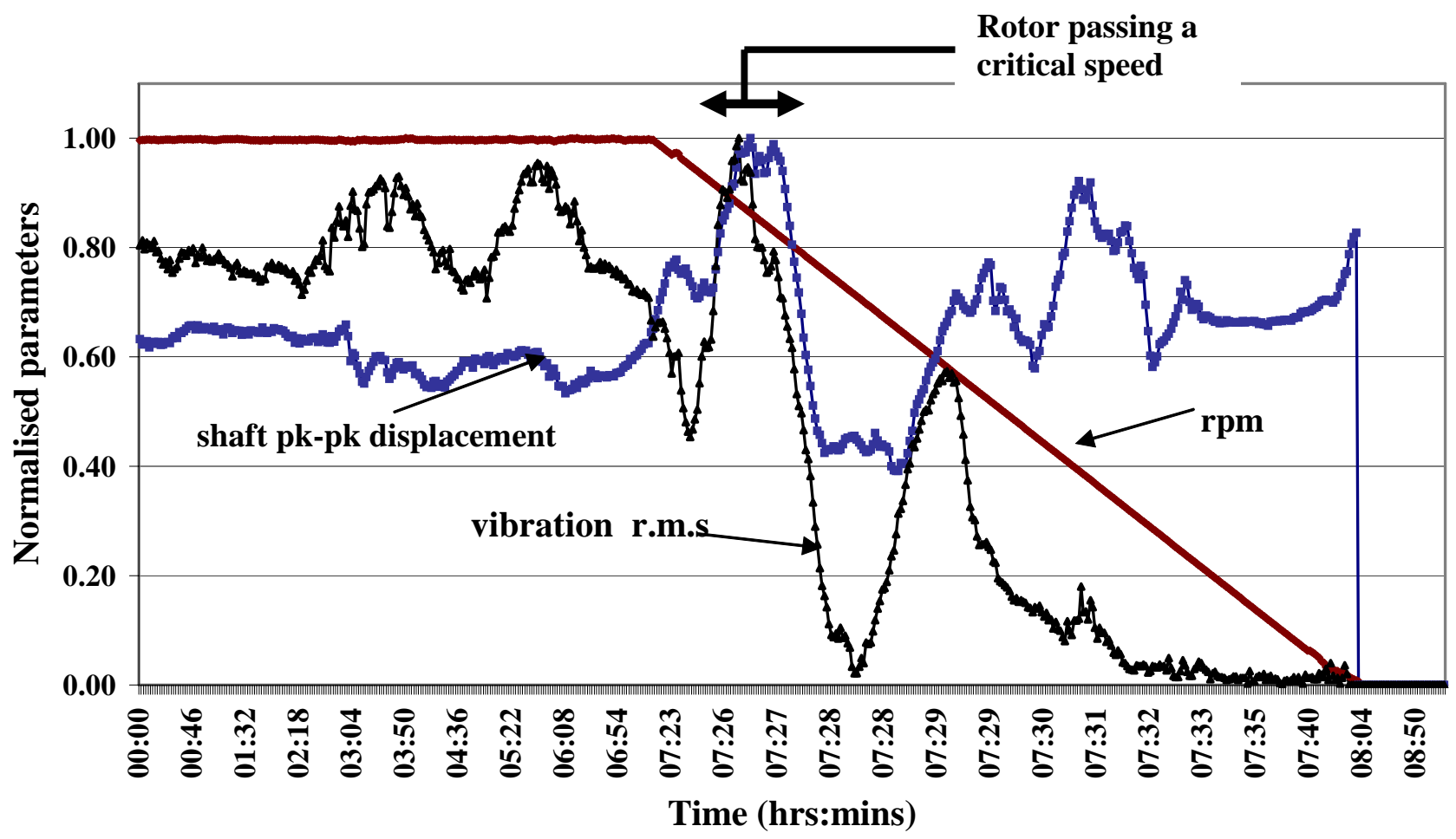

Figure 16 Speed, peak-to-peak displacement and vibration r.m.s during rundown; bearing 7

Clearly AE operational background noise levels at bearing 6 were higher than at bearing 7 during run-up and run-down. Initially, the authors believed that this difference in AE levels was related to the dynamic loading on the bearings, which would have a direct effect on the transmission and attenuation characteristics from the rotor to the bearing casing. This dynamic loading is dependent on the operational mode shape of the coupled turbine units. It was assumed that bearing 6 supported more load than bearing 7; the significance of this is that the oil film thickness will be less in bearing 6 than bearing 7; therefore bearing 6 will experience less relative attenuation of the $\mathrm{AE}$ signatures to the receiving sensor on the casing. However, observations of bearing temperatures and jacking oil pressures showed similar values, discrediting this postulation. The authors can only put this difference in operational 
background noise levels to the surface finish at the position of the sensor and the clamping force on the AE sensor. In positioning the sensors onto the bearing casing, paint was scraped off the casing thereby exposing the casing metal. The surface finish of this cast metal casing is off insignificance to the performance of the turbine unit and as such a large variation in surface finish exists across the casing. The authors could not guarantee an identical surface finish at the location of the sensors. It must be noted that a couplant was used to improve the contact area. Another reason for the variation in AE levels might be due to differences in the magnetic clamp force on the receiving sensors.

It is interesting to note that AE r.m.s levels from the bearings correlated with the unit running through a critical speed. Whilst the vibration r.m.s levels and shaft displacement measurements indicated a 2 to 5-minute duration of relatively high vibration as the rotor passed through its critical speed, the duration of AE activity from the point of the onset of resonance lasted approximately 15-minutes during rundown, see figure 12. Also during run-up, particularly at bearing 7 (see figure 14) the AE r.m.s levels increased as the unit went through its critical speed. During the period when the rotor passed a critical speed the turbine unit experienced approximately $4 \%$ of maximum load.

An observation during run-up was the cyclic machine phenomenon detected by AE r.m.s activity, see figures 17 to 20 . This cyclic observation occurred simultaneously on bearings 6 and 7, and the cyclic rate was $0.033 \mathrm{~Hz}$ (1-cyclce every 30-seconds). The exact reason for this phenomenon is unknown as the authors cannot attribute this to the opening or closing of the steam inlet valve nor any other obvious cyclic 
machine function. Furthermore, the frequency was so low that the authors rejected the view it arose from a structural resonance. However, the authors believe that this phenomenon is related directly to the dynamic process experienced by the unit during run-up. Closer inspection revealed the cyclic event occurred very early during the runup of the unit, and remained until after the critical speed was passed, see figures 21 and 22. In addition, it was noted that this cyclic event was not observed during rundown on either of the bearings. The authors can only attribute this observation to a thermal phenomenon on the bearings/turbine, ending once thermal equilibrium was reached.

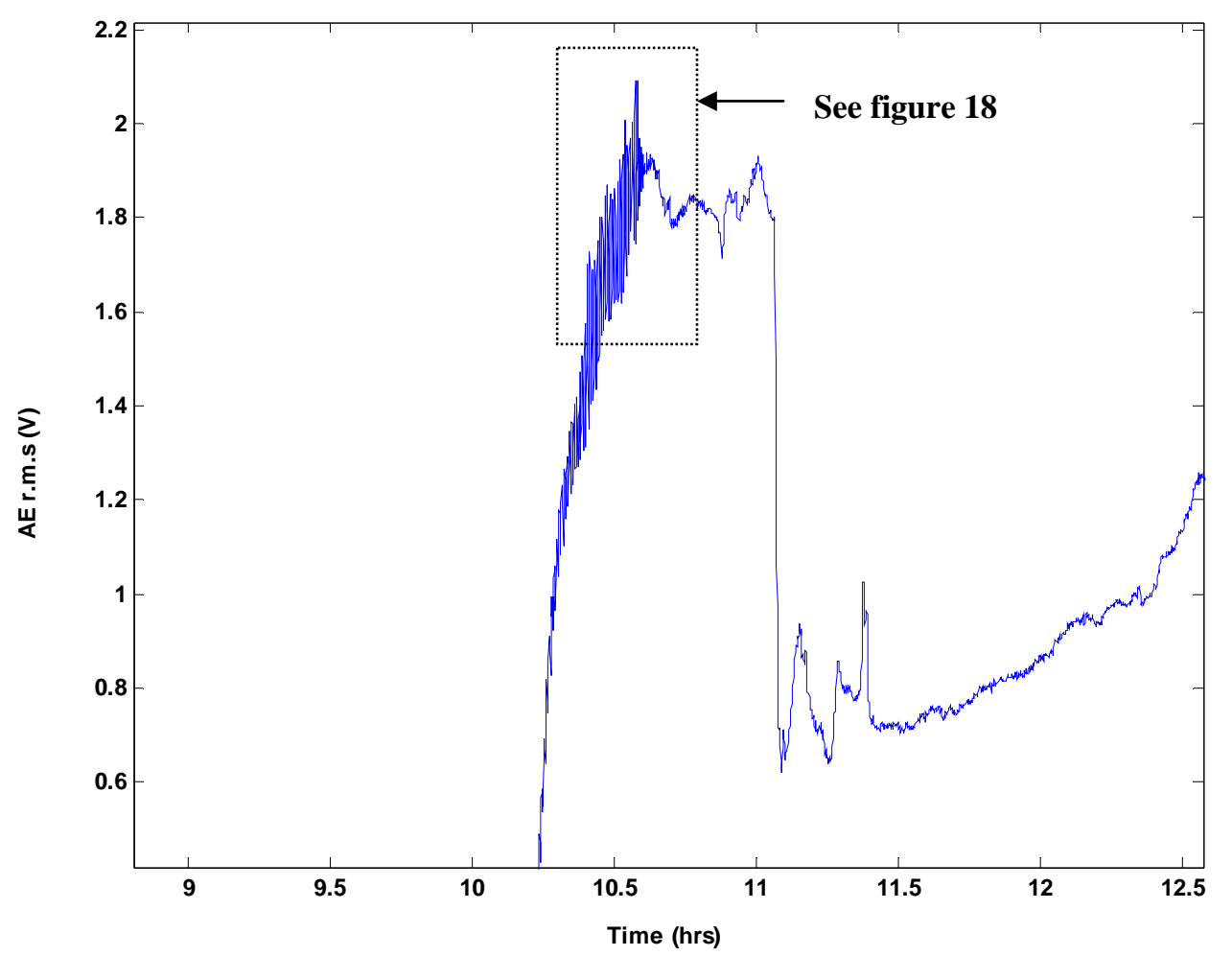

Figure 17 Observations of machine cyclic phenomenon with AE r.m.s activity during run-up; Bearing 7 
Tribology I nternational, 37 (5), pp. 415-422, 2004

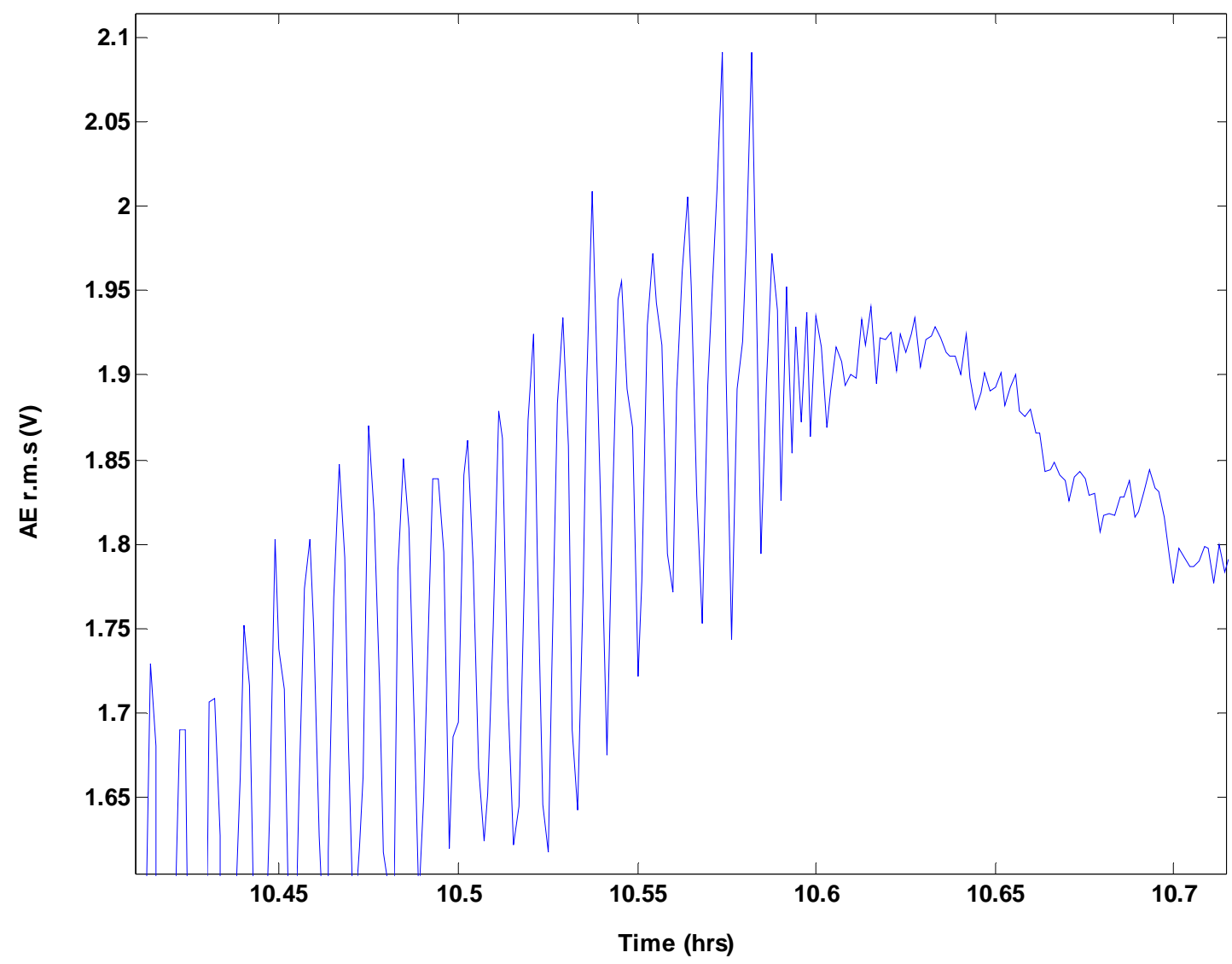

Figure 18 Observations of machine cyclic phenomenon with AE r.m.s activity during run-up; Bearing 7 
Tribology I nternational, 37 (5), pp. 415-422, 2004

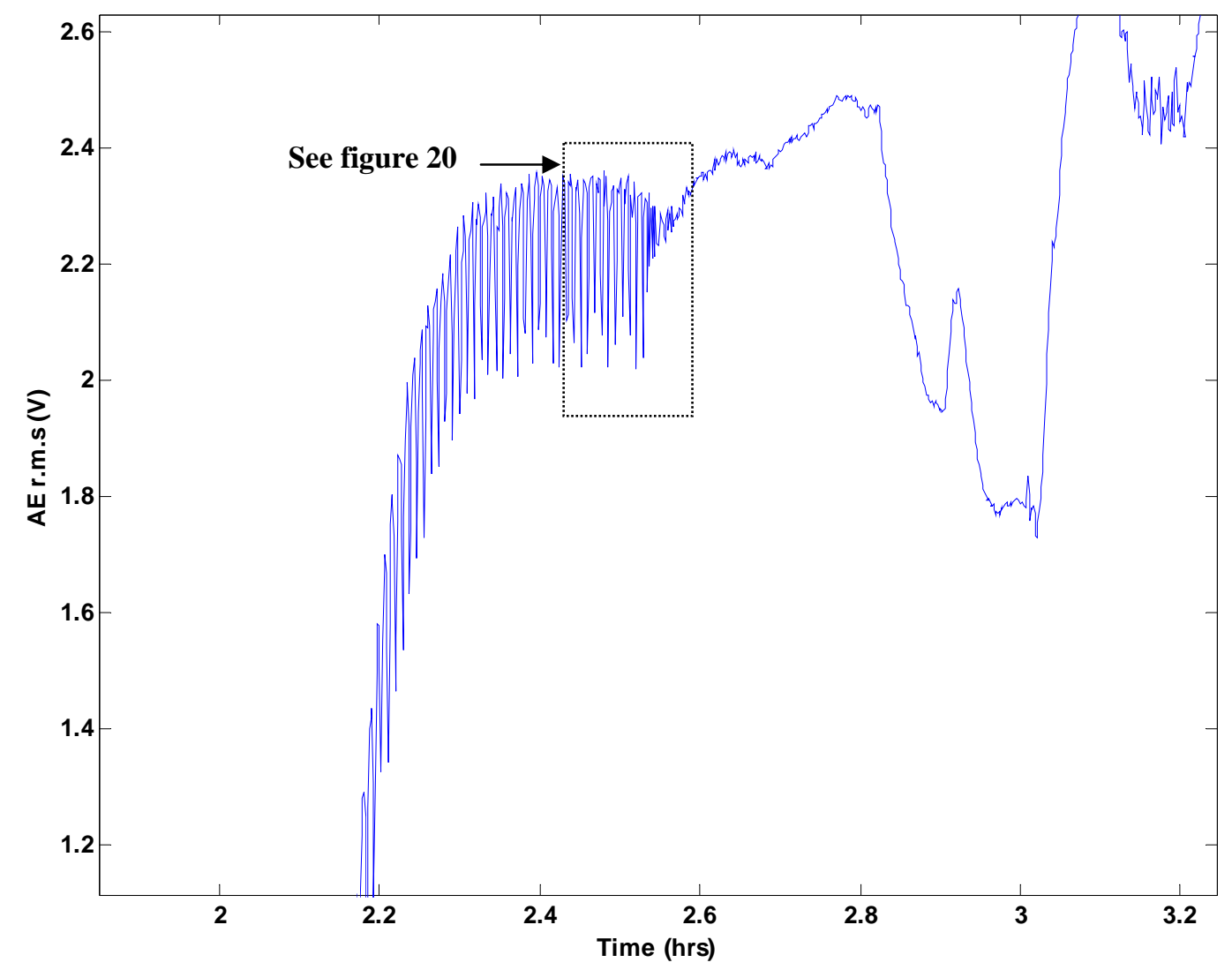

Figure 19 Observations of machine cyclic phenomenon with AE r.m.s activity during run-up; Bearing 6 
Tribology I nternational, 37 (5), pp. 415-422, 2004

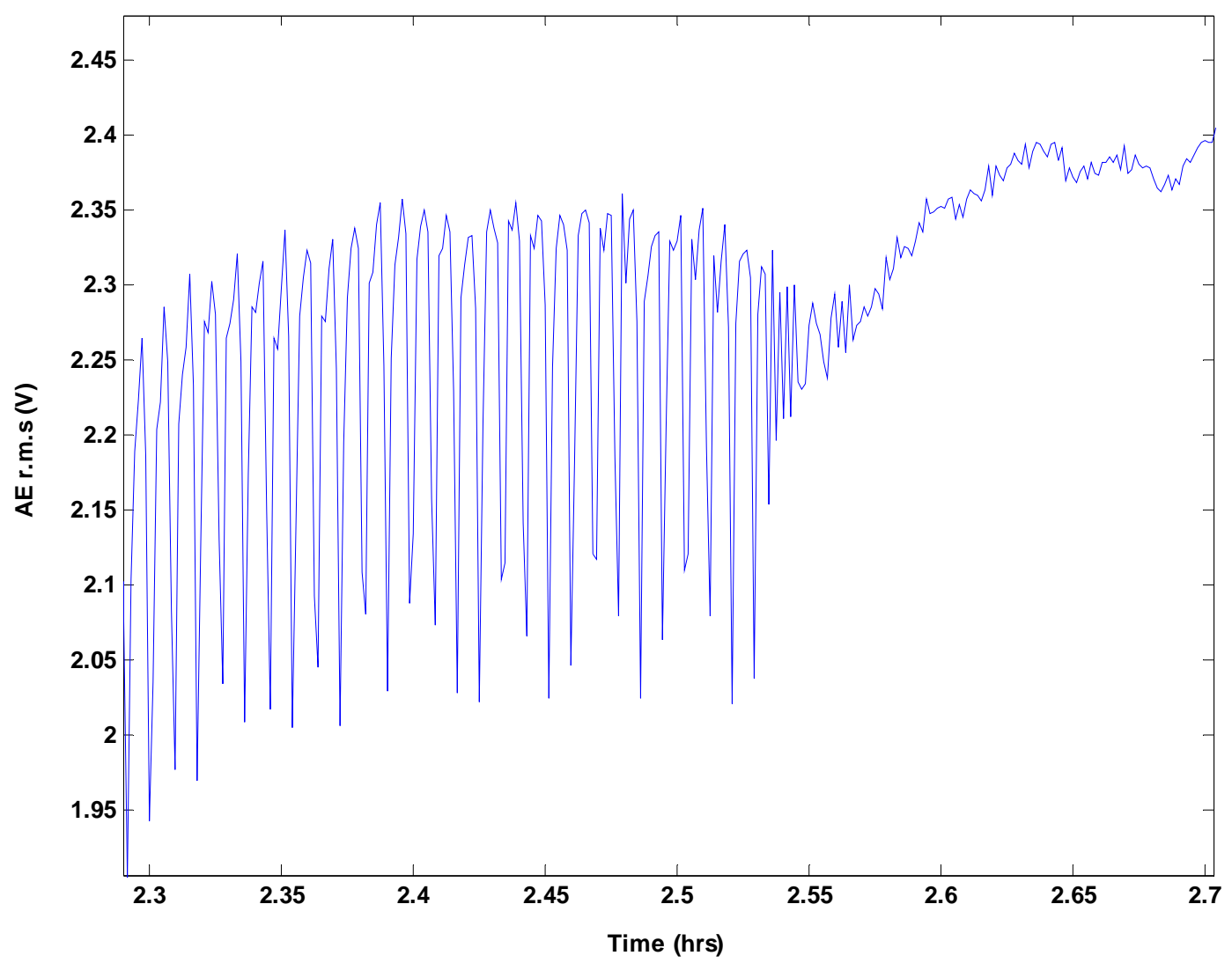

Figure 20 Observations of machine cyclic phenomenon with AE r.m.s activity during run-up; Bearing 6 
Tribology I nternational, 37 (5), pp. 415-422, 2004

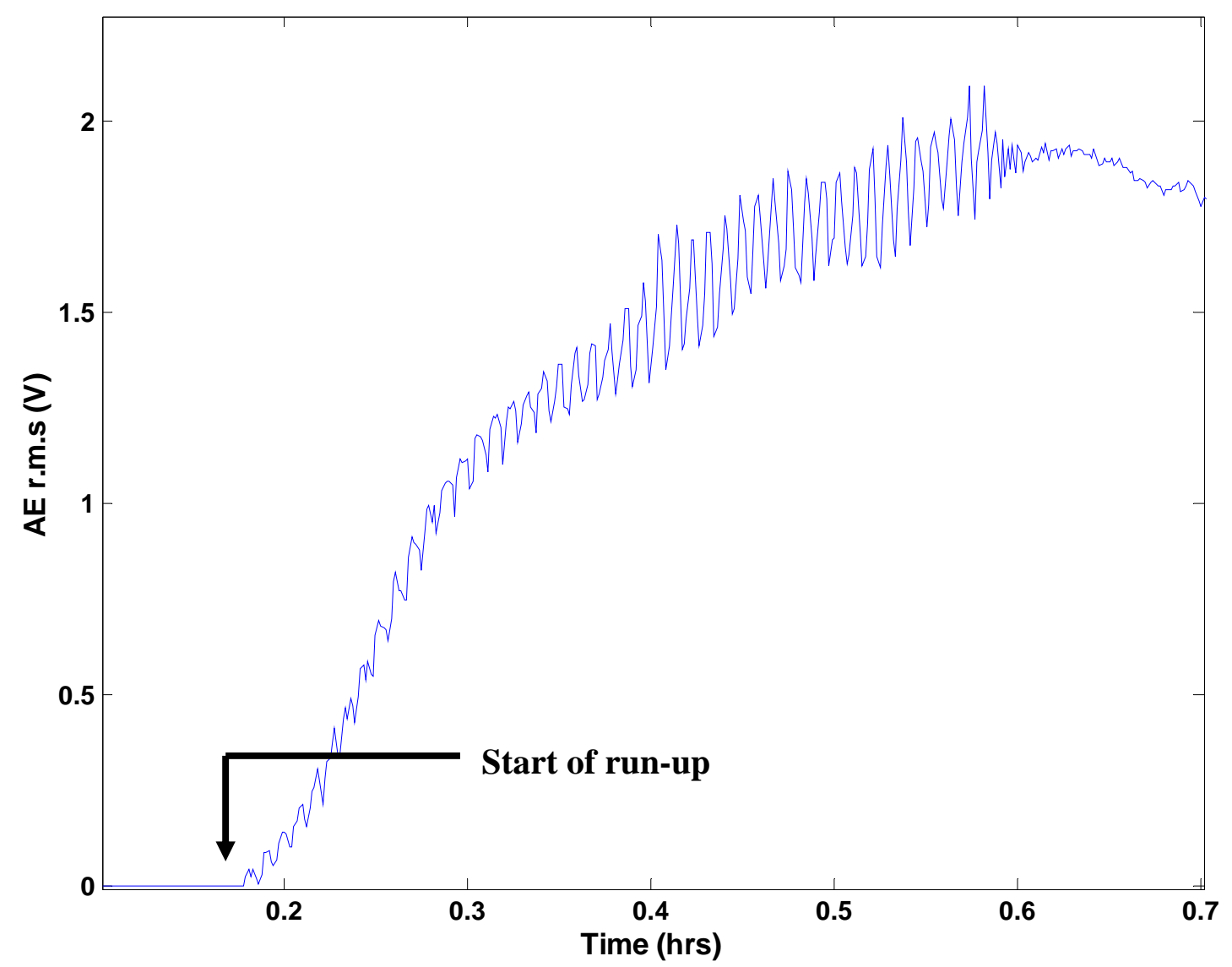

Figure 21 Observations of machine cyclic phenomenon with AE r.m.s activity during run-up; Bearing 7 


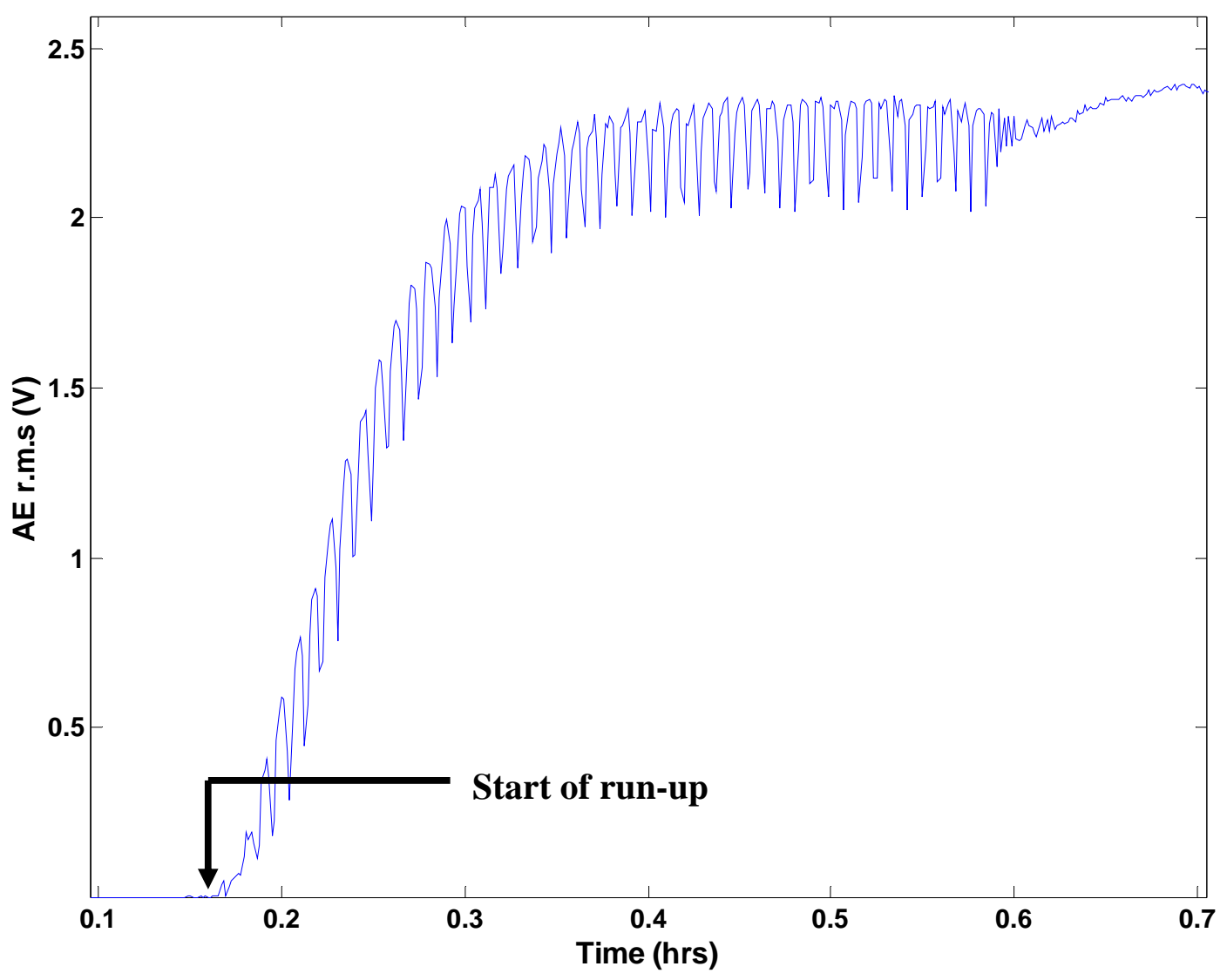

Figure 22 Observations of machine cyclic phenomenon with AE r.m.s activity during run-up; Bearing 6

From the results presented it was clear that the level of AE activity was a function of the loading on the turbine unit. In development of an AE monitoring system, the effects of this loading, and dynamic loading experienced on the bearings, must be given due consideration to ensure an effective system. It is postulated that as with vibration, AE activity is sensitive to the dynamic load experienced by the bearings, through in the case presented the loading was similar. In developing such a diagnostic/monitoring system, setting of alarm levels must be a function of the steam flow and bearing dynamic loading. The authors presented observations of the low frequency modulation of AE r.m.s for information purposes. 


\section{Conclusion}

The case study presented illustrates the relationship between AE activity and load experienced by the turbine unit. The sources of AE activity are attributed to steam flow, oil flow, aerodynamic turbulence at the blades and bearing friction. Furthermore, AE activity has been shown to detect a rotor passing through its critical speed. In establishing an $\mathrm{AE}$ monitoring system for power generation turbines due consideration must be given to the influence of loading on the turbine.

\section{Acknowledgements}

The authors wish to express their gratitude to Innogy Plc for allowing the publication of this investigation, undertaken as a Masters project on the MSc in Design of Rotating Machines, Cranfield University.

\section{References}

1. Sato I, Rotating Machinery Diagnosis with Acoustic Emission Techniques, Electrical Engineering in Japan, 1990; 110(2).

2. Armor, A. F, Graham, L. J., Frank, R. L. Acoustic Emission monitoring of steam turbines, Joint ASME/IEEE Power Generation conference, October 4-8, 1981, St. Lousi, Missouri, USA.

3. Mba, D., Cooke, A., Roby, D. and Hewitt, G. (2003). Opportunities offered by acoustic emission for shaft-seal rubbing in power generation turbines; a case study sponsored by the British Institute of NDT. International Conference on Condition Monitoring. Oxford, UK, 2-4 July 2003. pp 280-286, ISBN 1901892174. 
4. Mba, D, Hall,L . The transmission of Acoustic Emission across large-scale turbine rotors. NDT and E International, 2002, 35(8), 529-539.

5. M. Al Shaikh Mubarak, D. Mba, P. Cooper, Opportunities offered by acoustic emission for seal and blade rub detection on large scale power generation turbines, COMADEM 2003 International, The $16^{\text {th }}$ International Congress and Exhibition on Condition Monitoring and Diagnostic Engineering Management, August 2729, 2003. ISBN 91-7636-376-7. 